\title{
Simultaneous Moderation Effect of Industry Forces and Firm Resources on Entrepreneurial Orientation: A Case Study of Small Size Hotels in Ghana
}

\author{
Adelaide Spio-Kwofie, Ph.D, Ivy Fosua Osei, Sharon Atakpa , Eric Paintsil \\ Takoradi Technical University, Hospitality Department, P.O. Box 256, Takoradi, Ghana
}

\author{
DOI: $\underline{10.36348 / \text { sjbr.2020.v05i09.003 }}$ \\ | Received: 23.06.2020 | Accepted: 30.06.2020 | Published: 17.09.2020 \\ *Corresponding author: Sharon Atakpa
}

\section{Abstract}

This study has attempted to answer the impact of entrepreneurial orientation on business performance of small hotels in Ghana; the moderating effect of industry forces and firms' resource. Like any other empirical related study, four constructs, namely entrepreneurial orientation, industry forces, firms' resources, and business performance were used. The study adopted a survey research design that involves the use of quantitative sampling techniques for the primary data. A sample size of three hundred and ninety-six (396) owner-managers was emailed with a questionnaire to solicit for their responses. Analysis of the independent dimensions of entrepreneurial orientation showed significant correlations between each of the variables and hotel performance. The strategic use of firms' resource revealed that it positively moderates the relationship between entrepreneurial orientation and business performance. Although the hotel industry is turbulent, the strategic implementation of firms' resources neutralizes the strength of industry forces on the business performance. Again, strategic implementation of these resources increases business profitability, sales growth, customer retention, and customer satisfaction. The findings of this research contribute both to small business management and measurement theory, as well as providing a basis to guide small business policymakers, educators of hospitality management and hotel managers in general.

Keywords: Entrepreneurial Orientation; Industry forces; Firms' resources; Business performance; Small Size Hotels.

Copyright @ 2020: This is an open-access article distributed under the terms of the Creative Commons Attribution license which permits unrestricted use, distribution, and reproduction in any medium for non-commercial use (NonCommercial, or CC-BY-NC) provided the original author and source are credited.

\section{INTRODUCTION}

The existence of an entrepreneurial orientation (EO) in a firm is the result of organizational processes, methods, and styles implemented by the firm in the pursuit of acting entrepreneurially. As the field of strategic management developed, the emphasis shifted to the entrepreneurial process, that is, the methods, practices, and decision making styles managers use to act entrepreneurially. In 1990, business management was determined to be an appeal of sectors in which the company was competing and by the competitive position of the company in sectors. This emphasized the external firm's competitive advantage, based on capitalizing on the relative inadequacies of the sector in which the firms compete $[1,2]$. However, a recent idea of analyzing competitive advantage from an internal organization perspective has emerged $[3,1]$. The diverse nature of resources is an essential element in the development of business activity and plays a key role in the evolution of organizational performance. Hospitality businesses such as small size hotel (SSH) are one of the industries that are highly competitive with many competitors experiencing dynamic industry changes. Most organizations state their positions with the forces in environments in order to achieve sustained performances. Due to the special characteristics of the hotel industry and competitive of the industry, hoteliers are challenged to choose the competitive strategies leading to superior performance. For example, the hotel business will succeed only if hoteliers are able to see opportunities in the environment of the business, invest in adding competitive strategies, and allocate resources to these strategies and add the greatest profitability to the firm since neither entrepreneurial orientation nor industry forces nor firm resources acting alone are sufficient to explain the differences in performance.

\section{THEORETICAL AND PRACTICAL BACKGROUND \\ Practical Background}

Although much of the research literature in hospitality has focused on mainstream accommodation 
such as large hotels, recently more attention has been given to smaller accommodation such as guesthouses and bed and breakfasts. While acknowledging its significance, however, relatively little attention has been given to exploring the business performance of small size hotels ( $\mathrm{SSH})$. This may be due to the difficulties faced in researching such businesses due to their size and scale of operation. There is a number of significant gaps in published research regarding small size hotels and these include; entrepreneurial orientation and its influences on product/service, further exploration of the relevance of the lifestyle entrepreneur concept across the range of hotels, sustaining small hotels, information technology on hotels performance, quality service of small hotels among others [4, 5]. Thus, this research addresses a gap in the current body of literature and responds to calls by researchers and interested academics for a more sector-specific focus to be adopted with research that concentrates on issues important to the hospitality sector. Further, Porter's competitive advantage limited the ability of the industry to only the external forces while Barney's resources base advantage limit the firms' resources to only the internal resources. In analyzing the two, the outcome of this research will go some way into addressing many of these gaps in the literature, focusing on how small size owner/manager can improve performance through the use of the firms' internal resources in overcoming industry forces.

Taking into consideration that small-medium enterprise is an important driver in every economic development, the external and internal factors that enhance the business performance of small size hotels' in Ghana should be explored. In time past, people seek the service of the hotel without prior bookings as long as it meets its cleanliness standard. People still travel for business, pleasure, academic and therefore expect their money worth through the services obtained from the hotel. The perishable nature of hotel product has led to hotels competing for new customers as well as repeat business. The hotels' industry is dominated by SME's as statistics show an upward increase in the number of hotel businesses that keep springing up across the globe. Studies are yet to examine a broader range of how entrepreneurs are able to operate successfully in a competitive environment and achieve the following; growth, increase sales, enable customer retention, capture a greater share of the market and enhance firms' performance. Consequently, there is no specific theoretical framework for small hotel business performance in Ghana in which entrepreneurs can depend on as a guide when faced with business challenges that hinder growth or even a permanent shutdown. Therefore, it is critical and extremely important to identify and examine those that enhance business performance and be simulated for survival and success. The moderating influence of both industry forces and firms' competitive resources on the relationship between EO and hotel performance is not researched extensively like EO and firm performance. The moderating variables that are highlighted in the validated models can be adopted into didactic programs. A good comprehension of the vital information necessary for business operation enables Ghana small size hotel operators to effectively prepare for entry into markets where the rivalry among industry and the bargaining power of customers may be prevalent. The business environment can be considered to be turbulent in the context of SSH because of the challenges posed by large hotels. Therefore, the outcomes of this current research could help educators and counselors to identify the exact things to communicate to prospective and practicing entrepreneurs in Ghana particularly when entering into a new venture. Given that the business goals and personal goals of the entrepreneur are intertwined, it would be useful to formulate teaching curriculums that show the inter-connectivity between EO, firms' resources, industry forces and business performance issues.

\section{Theoretical Background}

Building on the works of Lumpkin and Dess [6], Barney [7] and Porter [8], the theories and extensive literature regarding entrepreneurial orientation, firms' resources, competitive advantage, and business performance were discussed. Many early studies contributed to the gradual establishment of EO as a theoretically and logically legitimate construct representing the entrepreneurial nature of a firm. Many early studies contributed to the gradual establishment of EO as a theoretically and logically legitimate construct representing the entrepreneurial nature of a firm. Prior to the formal development of EO, research examining entrepreneurial organizations identified many characteristics that distinguish organization from others. Such distinction included characteristics such as, organizational culture, environmental strategy, rates of growth, and leadership. The many characteristics listed above have received an amount of research, however, researchers such as [9-11, 6] one which seems to provide the most clarity as well as extensively used. Thus, the foundation of the entrepreneurial orientation construct was introduced, with the key elements being innovativeness, risk-taking, proactiveness and competitive aggressiveness.

Further, Porter [8] provides a framework that models an industry as being influenced by five industry forces and it is called Porter's five forces approach and these are the strength of each of the competitive forces function. The purpose of Porter's five forces model is to gain a thorough understanding of a particular industry by analyzing the external environments through analysis of five identified competitive forces. The industry forces theory is on an assumption that firms within an industry possess identified or similar resources. As a result, a firm's success, as in the case of $\mathrm{SSH}$, depends on how to react to market signals and 
accurately predict the evolution of the industry structure $[1,12]$. According to Porter [8], in any industry, e.g. hotels, the rules of competition is embodied in five competitive forces; entry of new competitors (entry of new hotel /entrants), the threat of substitutes (threat of new hotel products/service), the bargaining power of buyers, (hotel guest or customer) the bargaining power of suppliers (employees or suppliers of goods and services) and the rivalry among existing firms (competition among hotels).

For being competitive in market business [13, 14], cited J. Barney [7] resources as all assets, capabilities, organizational processes, firms' attributes, information, knowledge etc. controlled by the firm to enable it conceive of and implement strategies. Resources consist of financial capital (money form entrepreneurs, equity holders, bonds, banks and retained earnings) and physical capital (plant, equipment, land, natural resources, raw materials, computer hardware and software, manufacturing robots, automated warehouses, semi-finished goods, by products waste, unsold stock of finished goods and other tangible property) $[7,13,15,14]$. The resource-based analysis of competitive advantage comes from two basic empirical generalizations. First, there are systematic differences across firms in the extent to which they control resources that are necessary for implementing strategies. Secondly, these differences are relatively stable. The basic structure of the resource-based perspective emerges when these two generalizations combined with fundamental assumptions largely derived from economics. These assumptions are; differences in firms' resources endowments could cause performance differences and that firms seek to increase economic performance [16, 13]. To J. Barney [7], the firm must have competitive resource attributes in order to have any potential for competitive advantage. First, it must be valuable, in the sense that it exploits opportunities and /or neutralize threats in a firm's environment.

\section{LITERATURE REVIEW}

The highly competitive global markets today cause managers to strive to improve organizational effectiveness through the identification of organizational strategies. These competition force hospitality managers to seek sustainable competitive advantages in the business $[1,17]$. Strategy researchers argue that achieving a competitive advantage depends upon the firm's ability to utilize existing resources and its ability to accumulate new resources more efficiently and effectively relative to competitors [1, 17]. Industry forces are the primary determinant of hotels being competitive in every other hotel firm. The firm's competitive environment influences its ability to successfully carry out a chosen strategy. Without the appropriate form between industry forces and strategic utilization of resources, hotel firms may experience difficulty in achieving long-term success. Hotel firms should adapt themselves to the rapidly changing industry environments (industry five force factors approach), and continually develop new resources (resource-based approach) to achieve long-term growth and profitability. If hotel firms would like to be competitive in the business, they need to understand the links among industry, strategy, and performance $[1,2]$.

\section{Entrepreneurial Orientation and Business Performance}

Innovation has been viewed in several ways by researchers in the field of entrepreneurship. For instance, early researchers sought to dichotomize innovation as either product-market or technological (process) innovation. Early definitions of innovation focused on the extent to which an organization could develop new technologies or practices which were currently not available in a market. Researchers such as $[9,18]$ have viewed innovativeness as the efforts an organization put forth towards introducing new products, services, processes, technologies, systems, plans or structures. Innovation is important for firms in their early stages of development, because it helps hotel to create novel competitive offerings and thus meet the needs of the guest. By doing this, the hotels are more likely to get a foothold in the market, which is crucial in ensuring long-term success [9, 18]. For any SSH to operate, some level of risk must be included, and there is no such thing as business without risk. However, risk-taking in an EO perspective aims to circle out those firms that show an extra willingness to take additional risk to pursue opportunities. By taking on extra risk, hotels typically endures heavy debt or makes large resource commitments in the pursuit of seizing higher market-shares and thus expect higher returns. Risk in the view of EO is willingness to venture into the unknown. Risk is in fact regularly used to describe entrepreneurship as entrepreneurs differ from hired employees in that they accept the riskiness of selfemployment.

Proactiveness helps firms in anticipating market changes and acting accordingly, which allows the firms to have a strong position in shaping the competition in the market over time. This will in turn lead to improved performance as in the case of SSH. To [9, 11, 18], proactiveness has an important role especially in the introduction and growth stage of an industry's life cycle. Competitive Aggressiveness is firm's tendency to intensely and directly challenge its competitors in order to outperform rivals in the marketplace $[11,18]$. A SSH can achieve competitive aggressiveness by adopting unconventional tactics to challenge industry leaders. Outperforming a hotel in the marketplace is the essence of competitive aggressiveness. New hotels are in a vulnerable position and thus exposed to a high risk of being outperformed by established hotels. For SSH to possess competitive aggressiveness it must continuously and directly challenge its competitors especially the large hotels in 
order to achieve a competitive advantage and improved position.

\section{Competitive Advantage}

In every industry, the competitive advantage described it through five force factors; the threat of new entrants, the threat of replacing products, the suppliers' power of bargaining, the customers' power of bargaining and the rivalry among the firms of the same sector [15]. The industry forces approach is on an assumption that firms (hotels) within an industry possess identified or similar resources. As a result, a firm's success as in the case of hotels depends on how to react to market signals and accurately predict the evolution of the industry structure $[19,16]$.

The industry forces often examined collectively to determine the nature or intensity of competition in a given market. From the five force factors, threat of substitutes and bargaining power of suppliers did not seem to have a major influence on competitive strategy $[16,15]$ and this seems to be so in the case of the hospitality industry. Extant literature regarding the bargaining power of suppliers in hotel industry appears to be low because of the large number of suppliers $[12,15]$. This indicates no single supplier is dominating the commercial accommodation market. There is also the less threat of substitutes in hospitality industry $[15,20]$ and this occurs when hotels offer similar or mass product/service. Since the bargaining power of suppliers and threat of substitutes tend to have little influence on implementing resource competitive strategies, the hotel business mostly related to the customers/buyers, rivals, and new hotel entrants. Therefore, this study emphasized only on three force factors - rivalry among existing hotel firms, bargaining power of customers, and threats of new hotel entrants. The impact of bargaining power of suppliers and threat of substitutes were not included in this study.

Rivalry among Existing Firms is the degree of rivalry determining the extent to which the value created by an industry is dissipated through head-tohead competition $[21,22]$. Intense rivalry is the result of a number of interacting structural factors: numerous or equally balanced competitors, slow industry growth, high fixed or storage costs, lack of differentiation or switching costs, capacity augmented in large increments, and diverse competitors [21, 16]. Competitive intensity in hospitality industry has increased because of an increased number of operating units, new product introductions, and market entries of nontraditional products such as corporate housing [23, 15]. Rivalry occurs because competitors either feel the pressure or see the opportunity to improve position of products or services. In the case of differentiation among products, firms will use pricing strategy to attract customers. For hotel industry, most rivals are determined according to the similarity of price, segment, and proximity [22, 23]. Firms are not independent and affected by the actions of other firms. Therefore, the hotel firm should not treat the competitors equally, because competitors can influence the hotel firms in different ways. The competition is generally based on the quality and the consistency of rooms, restaurant, and meeting facilities and services, attractiveness of locations, availability of a global distribution system, price, and the ability to earn and redeem loyalty program points [22, 12]. Competitors with disproportionately strong resource bases can be aggressive and create a strong rivalry.

Bargaining Power of Buyers/Customers power increases the appropriation of the value created by an industry. The size and the concentration of customers are the determinant factors of buyer power, e.g. group of tourist, group of business travelers. Again, the concentration here also pertains to the number of buyers/customers against the number of hotels available for the customer. Invariably, the number of hotel rooms or facilities available outnumbers the buyers/customers per a specific demand. Buyers therefore compete with the industry by forcing down prices, bargaining for higher quality or more services, and playing competitors off against each other [24, 25] as new technology can provide customers reserving hotels from anywhere in the world. Many hospitality firms neutralize buyer's power by creating loyalty programs that reward customers for repeat purchases and reduce buyer's power by differentiating products and services offerings [21, 22].

New Market Entrants refers to the prospect of new competitors entering an industry. The most common barriers to entry are economics of scale, product differentiation, capital requirements, switching costs, access to distribution channels, cost disadvantages independent of scale, and government policy $[16,24]$. Although the hotel industry has high entry barriers such as a huge amount of investment required in building and furnishing, there still exists a threat of investing in hotels by companies or people with no experience in the industry. Hotel firms use their entry barrier through patented or proprietary expertise, restricted distribution channels, or difficulty in brand switching $[15,20]$. A key resource for successful firms is a competence in environment scanning, and understanding the environment helps hotels to create the competitive strategies, which will drive change in that environment. Depending on the environment, strategic management often chosen based it on the local conditions facing the hotel. The hotel business identifies the position in the market area and plan to fight against the competition that threatens strategic position before formulating strategies. The notion is that hotels must adopt a more dynamic strategy in order to defend themselves against industry structures and increases their market share $[15,20]$. 


\section{Utilizing the Hotel's Resource in Achieving Business Performance}

To J. Barney [7], understanding sources of sustained competitive advantage for firms has become a major area of research in the field of strategic management and it is with the assumptions that strategic resources are heterogeneously distributed across firms. To help focus the analysis of the impact of a firm's environment on its competitive position, for instance, $\mathrm{SSH}$, much of this type of strategic research has placed little emphasis on the impact of idiosyncratic firm attributes on a firm's competitive position. These environmental models of competitive advantage have assumed that firms within an industry (e.g. or hotels within a strategic group) are identical in terms of the strategically relevant resources they control and the strategies they pursue $[26,4]$ and that this heterogeneity will be very short lived because the resources that firms use to implement their strategies are highly mobile. The resource based view of the firm substitute's two alternate assumptions in analyzing sources of competitive advantage. First, it assumes that firms within an industry (or group) may be heterogeneous with respect to the strategic resources they control [7]. For that matter, the hotel resources in this study are brand image, information technology and human resources.

Branded hotels are now claiming a large market share, threatening the existence of independent hotels, and are spreading rapidly to many parts of the world and now dominate the room supply [27]. Research has revealed that most travelers prefer to stay in a branded hotel rather than an independent one, most probably because there is a lower perceived risk in choosing internationally recognized hotels. Therefore, it is becoming increasingly important to build and manage strong brands and this has forced marketers and brand managers to focus more on this issue of branding [26, 4]. Some studies report a direct relationship between brand image and loyalty and customer satisfaction in the hotel industry [27, 26]. Particularly, hotels have intensively developed from mere management organizations to hotel branding enterprises and currently face service differentiation issues with respect to competitors [26]. In fact, services may require a greater notion of branding than physical goods because of the inherent service characteristics: intangibility, inseparability, heterogeneity, and perishability The degree to which a customer is loyal to a particular brand depends on, among other issues, the degree to which they are satisfied with quality of the product or services $[26,14]$. When a hotel guest perceives quality of the service purchased exceeds their needs, wants, and expectations, they will patronize the service repeatedly.

Interrelationship of service quality \& brand image emphasized the extreme importance of brand image for service firms because when customers use the service, they see the firm and its resources by their judgment of interaction between them and their service providers. Conversely, they will not be satisfied and would not likely to return to the hotel at all, if brands' good image is spoiled. Customer consumption experiences determine what strength of a brand image they are going to develop and the most important memory of their experience is obviously the service quality leading to brand awareness. Hotel consumers remember, buy and repeatedly purchase a well-known brand's product, creating a process that develops brand loyalty.

Information technology (IT) in the hospitality context, is considered to be the hardware and software as well as the intellectual capacity (human ware) to develop, program and maintain related equipment. Technology is gradually becoming a critical source of sustainable competitive advantage in the hospitality industry, particularly in the areas of description, promotion, distribution, amalgamation, organization and delivery of hospitality products $[26,28]$. The use of IT, more than ever before is a major prerequisite in forming strategic alliances, developing innovative distribution methods and communicating with consumers and partners while satisfying consumer demand [29, 23]. Customers and partners alike tend to place greater importance on firms which utilize information technology to a greater extent than their competitors due to availability of information. Demographic or generational change has also affected the access to and use of information. Consumers are making their demands more urgent, expect convenience, and prompt action anytime and anywhere. Many hotel use the internet as a sales and marketing tool to advertise and promote their hotels and communicate with their customers [23]. Customer brand perception about a hotel is not only shaped by offline marketing communication (e.g. magazines, newsletters) but also from various online sources such as hotel websites, online third party websites, and social media (e.g. Facebook, Twitter). These online marketing tools used by hotels not only provide brand-related messages and hotel information but also help to communicate and reinforce their brand image and brand personalities [26, 23]. The continued growth of the internet affects the role of brand and the way hotel manage their brand image is changing. In order to remain competitive in the market, many hotels have developed information technology in order to gain the benefit of high conversion rates and lower distribution costs [29, 23]. From the perspective of consumers, ITbased systems are used as information distributors and reservation facilitators, which allow them to make bookings at a fraction of time, cost and inconvenience of traditional methods [28, 23]. The internet and web as in IT help hotels to provide the right information efficiently, at the right time to the right individuals. 
Firms' human resources (HR) is more often than not, the skills and abilities of owner/manager which affect the success/failure of any business. Extant research has concentrated on exploring which skills are fundamental for successful entrepreneurial action and organizational capabilities of the firms. The subsequent emergence of new economic activity is often guided by situational factors such as markets, customers, investors or social relations. Human resource (HR) are the most important firm asset, the ones that research, design, project and differentiate the firm from other firms [19, 14]. Vomberg et al., [14] cited Porter \& Millar [30] on the role of $\mathrm{HR}$ as competitive advantages at any firm and in recent years, management schools have begun to appreciate the importance of $\mathrm{HR}$ as a source of competitive advantage. People and developed systems are difficult to copy by competitors, so they provide a source of sustainable competitive advantage that plays an important role in the performance of the firm [29, 14]. In reality, most firms in their annual reports stress that people are the main asset of their firm. Researchers have argued that HR is the possible sources for sustained competitive advantage, though they also note that to do so, the employees must be both highly skilled and motivated, that is, a high-quality workforce [19, 4]. Competencies provide the bases for all forms of organizational action. They can serve as either facilitators or deterrents of entrepreneurial behavior, and influence the specific form of entrepreneurship in which the hotel engages. Of course, the type of resources and capabilities possessed by the SSH will also affect entrepreneurial activity. For example, owner-manager's ability to develop and maintain an entrepreneurial posture is contingent upon that hotel's culture.

Research has demonstrated that a firm's innovative capacity is affected by cultural norms which either encourage or discourage business-related risk taking [19, 31]. Likewise, the level of competitive proactiveness exhibited by a firm will be, in part, culturally determined. Just as culture may affect entrepreneurial posture, it is likely that entrepreneurial posture will help to shape a firm and in this regard a hotel $[19,4]$. Instead of operating within the traditional hospitality environment (e.g. encompassing housekeeping, food and beverage service), an introduction of other services involving multi-skilling may require work that impinges on areas such as fitness, beauty and care to cater more specifically to a female clientele [19, 31, 4].

\section{Hotels Competitive Strategies}

The concept of competitive advantage describes where the organization currently derives its ability to contribute more value than its competitors. It refers to the degree to which the organization, under free market conditions, meets the demand of a product market while simultaneously maintaining and growing its profit levels [29, 32]. As J. Barney [7] put it, a firm's competitive advantage develops valuable firm resources and skills to yield position advantages and obtains positive outcomes in terms of market shares and profitability. In Lin and $\mathrm{Wu}$ [32], competitive advantage is the ability of one company to outperform another because its managers are able to create more value from the resources of their proposal. Porter [8] referred to a competitive advantage as the strategy used for accomplishment over competitors. These could be three types of competitive advantages: cost advantage, differentiation, and focus. Differentiation advantage is the superiority over the resources and capabilities of the company and its employees. Differentiation occurs by market (e.g. setting standards, raising value/expectations); by location (e.g. city centers or resorts) or by facilities (e.g. offering leisure facilities). These forms maintain basic price command and create barriers to enter causing non-price based competition, and therefore raising profitability and reducing the loss of market share. Differentiation entails customers perceiving a consistent difference in important attributes between the firm's offerings and its competitors' offerings [29, 33]. Differentiation advantage conferred brand reputation, proprietary technology, or extensive sales and service network. Hotel brand name, image, and service that name implied build brand loyalty through tactics aimed at reinforcing differentiation factors [29, 34]. Differentiation involves the creation of a product or service perceived by its industry as unique. It selects one or more attributes that customers from an industry perceive as significant, uniquely positions itself to meet needs and rewarded for its uniqueness with a premium price. With a successful differentiation strategy, loyalty to the firm's product will increase the assumption that customers are not too price-sensitive $[33,34]$.

The hotel can charge premium prices for its products and services that are of better quality than others in the market are. Some implications for differentiation strategy are: the firm must provide some distinguishing characteristics such as superior quality, and the firm must continually seek to innovate in order to stay ahead of its rivals in quality and other differentiating attributes [33, 4]. Hotel managers can develop ways to differentiate themselves from competitors by entering market where their rivals are not located, or by using creative marketing plans in locations where many of their rivals are located [35, 36]. The important aspects of competitive advantage include sustained revenue, innovation and new product development/first to market, brand and reputation, advertising, media coverage, customer needs, customer service/satisfaction, employee relations, acquisitions and mergers, regulatory issues, political correctness, and information technology services that affect customer service $[35,36]$. Securing an accurate understanding of rival intentions and capabilities enables identification of competitive opportunity and gives an appreciation of competitive circumstances that 
pre-empt rival strategies [37, 33]. Analyzing and understanding the actions of rival entities forestalls the strengths and weaknesses of current competitor strategies, helps predict emerging industry opportunities and threats, provides possible strategic alternatives to the organization and assists in the identification of strategic uncertainties that require further monitoring over time. The timing and competitive position of tactics involved in the implementation of strategies determine the competitive advantage and profitability of the organization in relation to competition. Based on the literature reviewed above, it thus;

Hypothesis: firms' resources and industry forces moderate the relationship between entrepreneurial orientation and business performance

\section{Method of the Analysis}

The study was conducted in Ghana using the 2-star hotels, 1-star hotels, guesthouses and budget accommodations using the Ghana Tourism Authority (GTA) hotel directory for 2016. With the aid of the GTA hotel data directory, the researcher grouped the hotels based on the grades. Thus, all the two star hotels, one star hotels, guest houses and budget accommodations in Ghana were categorized as small size hotels. Taking into consideration the nature of the hotels in Ghana, the researcher used stratified sampling in selecting the population of 396 respondents. To enable the researcher obtain the responses suitable for this study, closed ended questionnaires with five point Likert scale were used. In all, the questions were categorized into sections such as the entrepreneurial orientation, industry forces, firms' resources, and business performance of small size hotels.

\section{The Structural Equation Model}

Structural equation modeling (SEM) technique was used to generate a simultaneous statistical test. The SEM method can test for exact model fit and works perfectly in explanatory and predictive research [38]. Similarly, SEM is a well-established variance-based SEM technique that recently gained acceptance across many disciplines [38]. SEM is also more appropriate than covariance based-SEM for analyzing models with second-order constructs and moderating variables [38] and the analysis permits for the conceptualization of a hierarchical model through the repeated use of the manifest variable. All these forms the basis of using the SEM technique for this research. The interaction of the industry forces and firms' resources on entrepreneurial orientation and business performance is depicted in a simple conceptual model in Figure-1.

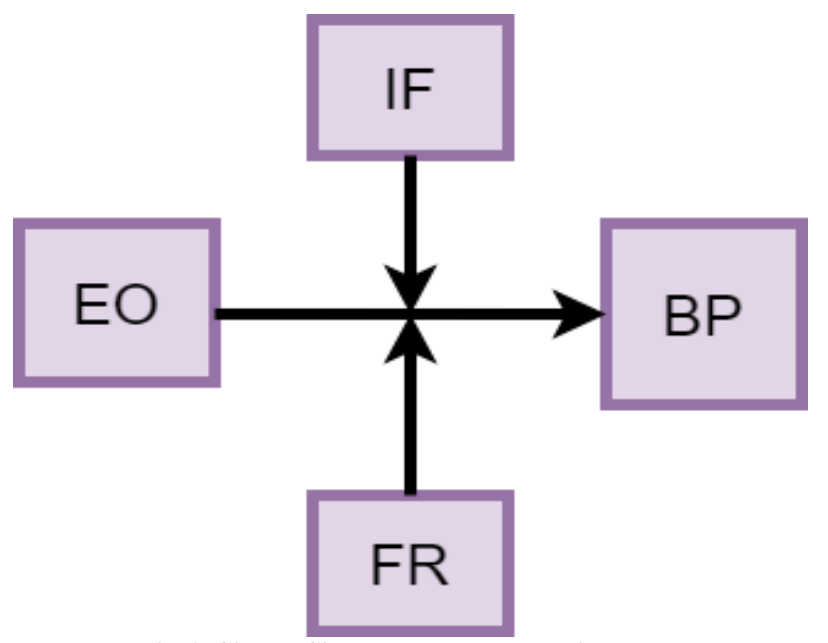

Fig-1: Simple Simultaneous Moderation

As shown in Figure-1 of this model, entrepreneurial orientation's effect is moderated by industry forces and firm resources simultaneously. The EO represent entrepreneurial orientation, BP represent business performance while the IF represents industry forces and FR firms' resources. Thus, it is assumed that the interaction of the two moderation (industry forces and firms' resources) effect the influence of entrepreneurial orientation on business performance. In other words, a change in either IF or FR increases or changes the effect of EO on BP also.

\section{Kaiser-Meyer-Olkin (KMO) and Bartlett's Test}

The Kaiser-Meyer-Olkin (KMO) measure of sampling adequacy and Bartlett's test of Sphericity tests help to indicate whether the data used in this study is suitable for structure detection. Specifically, the KMO test is a statistic indicating the proportion of variance that might be caused by some underlying factors. From Table-1, the test value of the KMO for the constructs used in the study (entrepreneurial orientation, industry forces, firms' resources and business performance) was given as 0.913 . This value is very high (closer to 1 ) and hence gives the general indication that a substantial proportion of variance (about 91.3\%) have been explained by the factors under discussion. Also, the value of the KMO test gives an indication that the sample is adequate for a factor analysis. Additionally, the Bartlett's test of Sphericity tests the hypothesis that the correlation matrix is an identity matrix. The 
Bartlett's test of Sphericity test from the Table 1 gives a p-value less than the level of significance leading to rejection of the hypothesis. This therefore implies that, the variables in the correlation matrix are related and hence suitable for structure detection (factor analysis).
In the nutshell these tests (Kaiser-Meyer-Olkin (KMO) and Bartlett's test) show that, the data used in the study is adequate enough for structure detection or factor analysis. Table1 shows the KMO and the Bartlett's test.

Table-1: KMO and Bartlett's test

\begin{tabular}{|l|c|c|}
\hline \multicolumn{2}{|c|}{ Kaiser-Meyer-Olkin Measure of Sampling Adequacy } & $\mathbf{0 . 9 1 3}$ \\
\hline Bartlett's Test of Sphericity & Approx. Chi-square & 356.179 \\
\cline { 2 - 3 } & Df & 276 \\
\cline { 2 - 3 } & Sig. & 0.000 \\
\hline
\end{tabular}

\section{Structure Model Showing Factor Loadings}

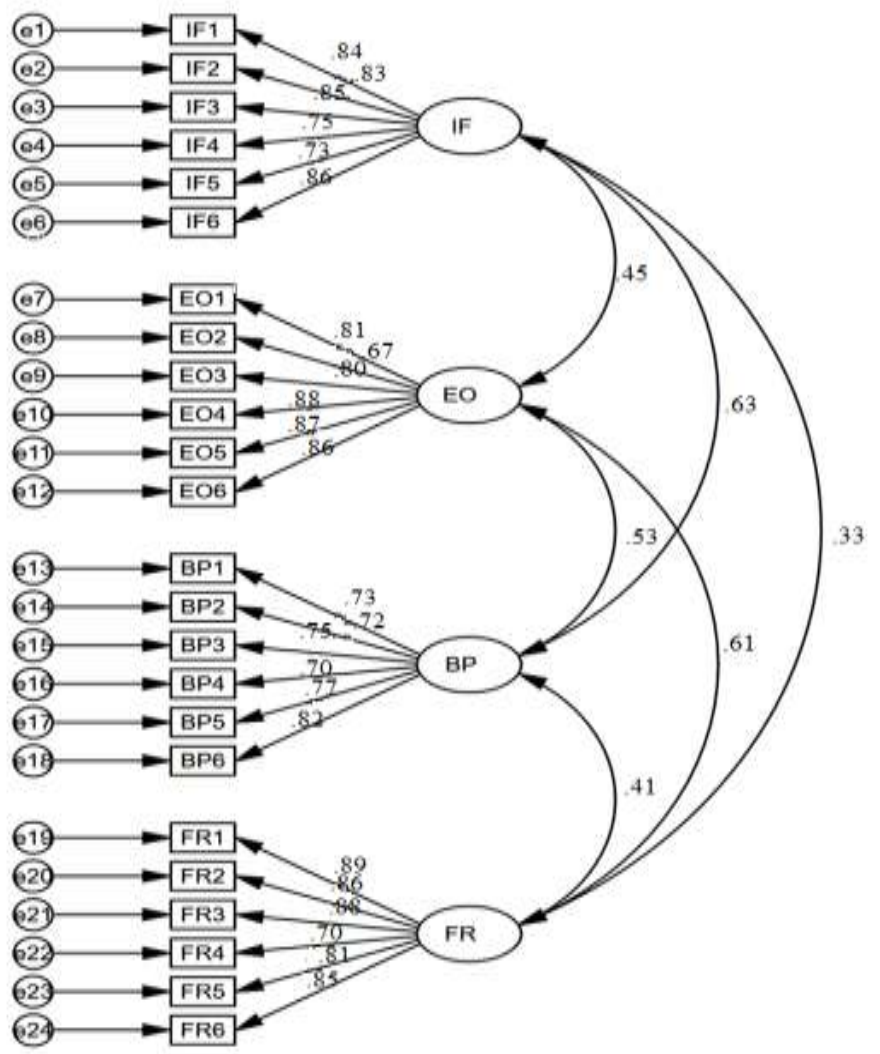

Fig-2: Structure of Factor Loadings

Figure-2 is a structural model showing the respective factor loadings of the observed variables of the various constructs in the model. It is observed from Figure 2 that all the factor loadings of the observed variables for IF exceeded the minimum threshold and that adequately explain the latent variable. Similarly, factor loadings for all observed variables for EO as well as FR were also above the minimum threshold as indicated. Further, factor loadings for the observed variables for BP exceeded the minimum threshold.

\section{Exploratory Factor Analysis (EFA) and Reliability Test}

Exploratory Factor analysis was conducted to examine the factor structure of each variable presented in the conceptual model. In accordance with Hair Jr, Hult, Ringle, and Sarstedt [39] it was decided that in order to reduce the number of items and to facilitate interpretation, principal component analysis with the orthogonal rotation (Varimax rotation) was used. This was performed for the measures of entrepreneurial orientation, industry forces and firms' resources. The use of this technique is consistent with the research works of social science scholars as this is commonly used when statistical independence is assumed between the factors. The orthogonal rotation (Varimax rotation) factor matrix also helps to generally improve the explanatory ability and offer sound or rich theoretical factor pattern [39]. Thus, in specific terms, the orthogonal rotation is the best approach for uncorrelated factors less than .15. Exploratory factor analysis (EFA) with the orthogonal rotation (i.e., Varimax rotation) extracted factors for items assessing business performance. A factor is retained based on the Eigen 
value greater than 1.0 criterion. Each measure with satisfactory internal consistency with a Cronbach's alpha value above .70. The EO with respect to these variables (innovation, risk taking, proactiveness and competitive aggressiveness) had an Eigen value of 1.593 and explained 8.15 percent of the variance retained in the items. The Cronbach's alpha for this factor was 0.891. With regards to industry forces, variables such as (fear of new entrants, bargaining power of buyers and rivalry among firms) had an Eigen value of 3.681 and explained 17.23 percent of the variance retained in the items. The Cronbach's alpha for this industry forces was 0.851. Further, firms' resources with observed variables such as (brand image, information technology and human resources) had an Eigen value of 4.756 and explained 20.45 percent of the variance retained in the items. The Cronbach's alpha for firms' resources was 0.807 . This is represented in the Table-2.

Table-2: Exploratory factor analysis (EFA) for EO, IF, FR, BP

\begin{tabular}{|c|c|c|c|c|c|c|c|}
\hline Constructs & Items & Loadings & AVE & CR & Cronbach's alpha & Eigen val. & $\%$ variance \\
\hline \multirow{6}{*}{ Firm Resource (FR) } & FR1 & 0.893 & \multirow{6}{*}{0.702} & \multirow{6}{*}{0.759} & \multirow{6}{*}{0.807} & \multirow{6}{*}{4.756} & \multirow{6}{*}{20.45} \\
\hline & FR2 & 0.867 & & & & & \\
\hline & FR3 & 0.880 & & & & & \\
\hline & FR4 & 0.704 & & & & & \\
\hline & FR5 & 0.816 & & & & & \\
\hline & FR6 & 0.858 & & & & & \\
\hline \multirow[t]{6}{*}{ Business Performance(BP) } & BP1 & 0.735 & \multirow{6}{*}{0.633} & \multirow{6}{*}{0.893} & \multirow{6}{*}{0.857} & \multirow{6}{*}{4.327} & \multirow{6}{*}{19.91} \\
\hline & $\mathrm{BP} 2$ & 0.721 & & & & & \\
\hline & BP3 & 0.756 & & & & & \\
\hline & BP4 & 0.700 & & & & & \\
\hline & BP5 & 0.772 & & & & & \\
\hline & BP6 & 0.828 & & & & & \\
\hline \multirow[t]{6}{*}{ Industry Forces (IF) } & IF1 & 0.841 & \multirow{6}{*}{0.674} & \multirow{6}{*}{0.749} & \multirow{6}{*}{0.851} & \multirow{6}{*}{3.681} & \multirow{6}{*}{17.23} \\
\hline & IF2 & 0.836 & & & & & \\
\hline & IF3 & 0.858 & & & & & \\
\hline & IF4 & 0.759 & & & & & \\
\hline & IF5 & 0.732 & & & & & \\
\hline & IF6 & 0.862 & & & & & \\
\hline \multirow{6}{*}{$\begin{array}{l}\text { Entrepreneurial Orientation } \\
\text { (EO) }\end{array}$} & EO1 & 0.814 & \multirow{6}{*}{0.659} & \multirow{6}{*}{0.915} & \multirow{6}{*}{0.891} & \multirow{6}{*}{1.593} & \multirow{6}{*}{8.15} \\
\hline & $\mathrm{EO} 2$ & 0.679 & & & & & \\
\hline & EO3 & 0.803 & & & & & \\
\hline & EO4 & 0.888 & & & & & \\
\hline & EO5 & 0.870 & & & & & \\
\hline & EO6 & 0.862 & & & & & \\
\hline
\end{tabular}

Note: AVE=Average Variance Extracted, CR=Composite Reliability

From Table-2, it can be contended that all the constructs are reliable. The values for both Cronbach's alpha coefficient and composite reliability are greater than the 0.7 expected in the initial stages of a study research and then the stringent value of 0.8 for basic research $[40,41]$. The AVE should be greater than 0.5 , suggesting that at least $50 \%$ variance of the indicators should be accounted for. All the constructs of the model exceeded this condition as seen in (Table-3). A comparison of the square root of the AVE (i.e., Table-3 diagonals) with the correlations among constructs (i.e., the lower triangle of the matrix in Table-3) determines discriminant validity. On average, each construct has a stronger relationship with its own measures than with others' as argued by [40, 41]. Table- 3 shows the construct's correlation matrix means and standard deviations.

Table-3: Fornell-Larcker Criterion for Discriminant validity

\begin{tabular}{|l|l|l|l|l|l|l|l|l|}
\hline Constructs & Mean & SD & AVE & $\mathbf{1}$ & $\mathbf{2}$ & $\mathbf{3}$ & $\mathbf{4}$ & $\mathbf{5}$ \\
\hline 1. Firms' Resources & 3.258 & 1.282 & 0.702 & $\mathbf{0 . 8 3 8}$ & & & & \\
\hline 2. Business Performance & 3.446 & 1.219 & 0.633 & 0.691 & $\mathbf{0 . 7 9 6}$ & & & \\
\hline 3. Industry Force & 3.699 & 1.308 & 0.674 & 0.503 & 0.604 & $\mathbf{0 . 8 2 1}$ & & \\
\hline 4. Entrepreneurial Orientation & 3.593 & 1.184 & 0.659 & 0.598 & 0.629 & 0.686 & $\mathbf{0 . 8 1 2}$ & \\
\hline
\end{tabular}

Note: $\mathrm{SD}=$ Standard Deviation, AVE = Average Variance Extracted 


\section{MODEL FIT ASSESSMENT}

In structural equation modeling, an assessment of the measurement and structural models are performed simultaneously. According to Hair Jr et al., [39] the assessment of the measurement model usually should precede the model structure. The assessment of the overall measurement model fit was performed using confirmatory factor analysis (CFA) and the maximumlikelihood estimation technique to establish whether the model is acceptable. Thus, this exercise establishes how well the relationship between the observed indicators and the unobserved latent variables match the model, and as well specifying the pattern by which each measure loads on a particular factor [39]. Under each construct, the observed variables that had poor loadings were removed. In trying to determine if there was opportunity to improve the model, model fit indices were consulted. Accordingly, the error terms between and among retained or captured observed variables under each of the latent constructs were co-varied. The observed variable under each latent variable were adequately correlated and met criteria of reliability and validity.

Test of goodness-of-fit of the measurement model was performed using a range of indices tests including, the chi-square test $=737.170, \mathrm{CFI}=0.972$, RMSEA $=0.014$, and SRMR $=0.038$, P Close $=0.975$. These tests from Table 4 based on the column labeled give the indication that, the measurement model is a good fit. Following [39] cut-off criteria in covariance structure analysis, the values realized for factor structure analysis demonstrate sufficiently that, the complete measurement model including all the variables fit the data appropriately. This is presented in Table-4.
Table-4: Model Fit Summary

\begin{tabular}{|l|c|}
\hline Statistic & Estimation model \\
\hline CMIN & 737.170 \\
\hline CFI & 0.972 \\
\hline RMSEA & 0.014 \\
\hline SRMR & 0.038 \\
\hline Pclose & 0.975 \\
\hline
\end{tabular}

Note: $\mathrm{CFI}=$ Comparative Fit Index, RMSEA= Root Mean Square Error of Approximation, SRMR=Standardized Root Mean Square Residual. For the model to be a good fit p-value of Chi-square statistic must be greater than 0.05 , CFI value must be greater than 0.90 whereas RMSEA and SRMR values must be less than 0.08 .

\section{ANALYSIS OF RESULTS}

The final model Figure-3 supports the hypotheses at $5 \%$ significant level. The prediction that Entrepreneurial Orientation influence Business Performance was supported with $(\beta=.645, \mathrm{t}=20.156$, $\mathrm{p}<.01)$. The prediction of the relationship between Firms' Resources and Business Performance was supported with $(\beta=.532, \mathrm{t}=17.433, \mathrm{p}<.01)$ and Industry Forces and Business Performance was $(\beta$ $=.423, \mathrm{t}=14.586, \mathrm{p}<.05)$. Further, the prediction of interaction effect of Firms' Resources and Entrepreneurial Orientation on Business Performance was also supported with $(\beta=.270, t=7.941, p<.05)$ and the interaction effect of Industry Forces and Entrepreneurial Orientation on Business performance finally gave a ( $\beta$-value of .112 with a t-value of 4.307 and $\mathrm{p}<.05$. The moderation effect of Industry forces and Firm resources on Business performance with the results was identified to be statistically significant at $5 \%$ level.

\section{Structural Model Output of the Moderation of IF and FR on EO. Structural Output of the moderation of IF and FR on EO}

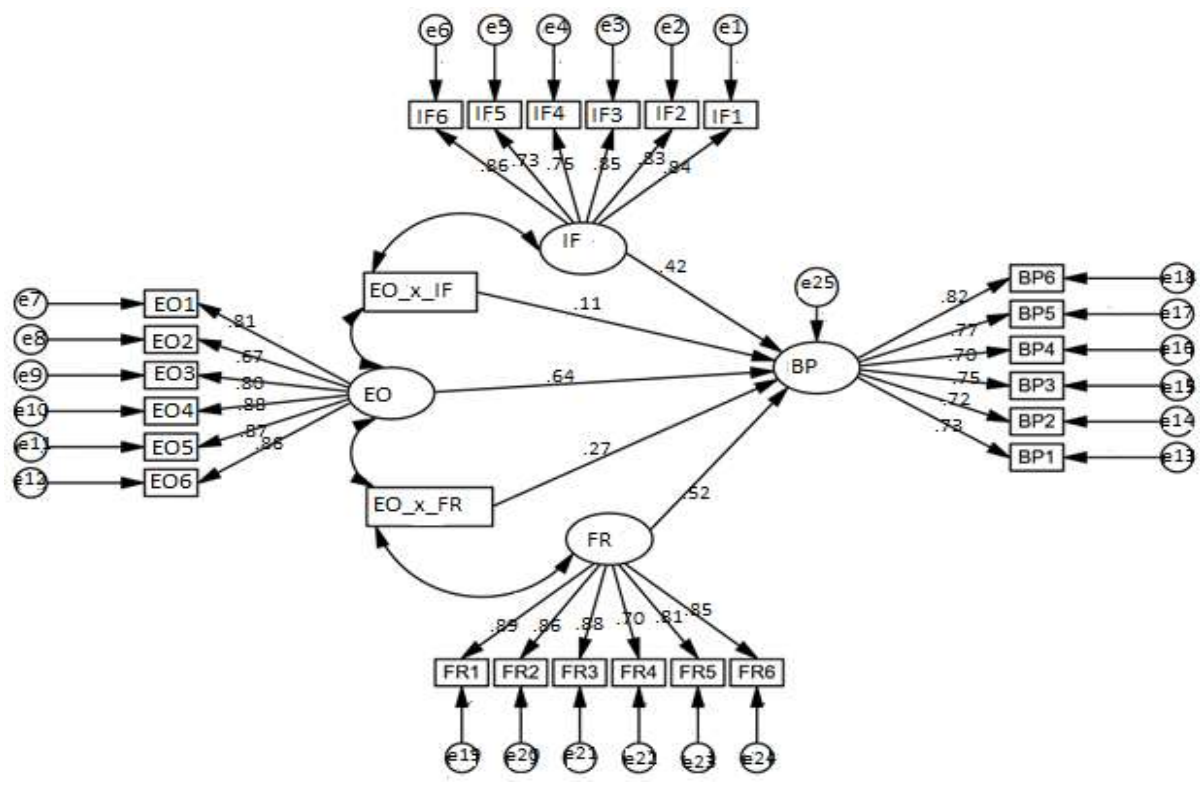

Fig-3: Structural Model of Moderation of IF and FR on EO 
Table-5: Path coefficient of the regression weights

\begin{tabular}{|l|l|l|l|l|l|l|}
\hline \multicolumn{2}{|l|}{ Paths Relations } & Estimate & S.E. & t-values & P-values \\
\hline BP & $<---$ & EO & .645 & .032 & 20.156 & .003 \\
\hline BP & $<---$ & FR & .523 & .030 & 17.433 & .006 \\
\hline BP & $<---$ & IF & .423 & .029 & 14.586 & .012 \\
\hline BP & $<---$ & EO_x_FR & .270 & .034 & 7.941 & .031 \\
\hline BP & $<---$ & EO_x_IF & .112 & .026 & 4.307 & .041 \\
\hline
\end{tabular}

To test the path coefficient of the variables, it first tested the relationships among the variables and then the interactive path was standardized using EO \& FR and EO \& IF variables and then created product variables (EO_x_FR) and (EO_x_IF). This interactive path was found to be significant at a $99 \%$ confidence level as shown in Table 5. From the analysis, it is observed that entrepreneurial orientation positively and significantly influences business performance. It is therefore fair to conclude the assumption that EO positively and significantly impacts on a firm's business performance is supported with a p-value of .003. This implies that an increase in EO translates into about 0.645 unit increase in business performance. By extension, it also implies that the development of entrepreneurial orientation by small hotels facilitate high business performance which is consistent with the literature. In effect, the result indicates that by developing entrepreneurial capabilities such as proactiveness, risk-taking behavior, and innovativeness, helps small hotels to achieved increased business performance. Secondly, it is observed from the model in Table 5 that firm resource positively and significantly impacts business performance. That is, the assumption that firm resource positively and significantly impacts small hotels' business performance is supported with a significant $\mathrm{p}$-value of .006. This result implies that a unit increase in firm resource will lead to a corresponding increase of 0.523 unit in business performance. This can be explained to mean that small hotel firms are likely to increase business performance by developing their brand image, information technology, and human resource capacity. This result further proves that information technology, as well as brand image and human resource, are key ingredients in the pursuit of higher business performance by small size hotels. This is clearly supported as espoused in the extant literature, in furtherance to this, industry forces positively and significantly impact small hotels' business performance is supported with a significant p-value of .012. This result implies that a unit increase in industry forces will lead to a corresponding increase of 0.423 unit in business performance.

From the interactive variable, the endogenous variables were standardized which created interactive variable EO_x_FR and EO_x_IF. It is observed from the result in Table 5 that the interactive path was positive and significant implying that when the two variables i.e. entrepreneurial orientation and firms' resource interact and entrepreneurial orientation and industry forces interact, the interactivity process thus exerts a greater impact on business performance at a value of 0.270 and 0.112 respectively. Thus, indicating a quantum leap in firm resources to impact on business performance of small size hotels. This also shows that the interactive variable supports our assumption that the intervention of entrepreneurial orientation and firms' resource yield higher impact on business performance of small size hotels. This also explains the crucial role played by firm resources in achieving higher business performance in the operations of $\mathrm{SSH}$. That is, achieving higher business performance by $\mathrm{SSH}$ is contingent on the hotel's ability to develop sufficient entrepreneurial orientation positively moderated by firm resources to overcome industry competitiveness.

\section{PRACTICAL IMPLICATIONS}

The study clearly indicates that innovation in the SSH is key to performance. This implies that innovation is a key determinant for higher business performance in the small hotel industry. This is confirmed in the extant literature that innovation enables hotels to gain a competitive advantage. However, managers of hotels should not lose sight of the fact that complacency in this highly competitive industry could give away some number of shares to new entrants who could take advantage of gaps in product offerings. The study averred that EO as a key characteristic of hotel managers is an enabler that impact positively and significantly on business performance. The implication is that, for hotels to realize improved business performance, hotel managers in Ghana are required to implement strategic decisions in order to be proactive, aggressive and innovative in order to stay competitive to survive on the market.

Again, it is observed from the study that the simultaneous moderation effect of industry forces and firms' resources between EO and business performance is not very high. This implies that, in the Ghanaian hotel industry, the combined effect effectively moderate the relationship between the constructs EO and business performance averagely. This phenomenon may occur due to the fact that when two moderators (i.e. industry forces and firms' resources) moderate simultaneously, the relationship, one of the moderator's impacts is subdued making the combined effect lesser than expected. In view of this, hotel managers in Ghana should realize that strategically it would be prudent to adopt the combined moderation strategy when measuring the impact of EO on business performance. It is therefore safe to categorically state that based on 
the findings of this study that hotels will be able to realize a higher business performance when industry forces and firms' resources moderate the relationship between EO and business performance.

Although the simultaneous moderation effect was not as high as expected, it is believed the firms' resources contribute positively and significantly to the attainment of the dependent variable (i.e. business performance). Taking into consideration the value obtained from the simultaneous moderation effect, it is believed firms' resources such as human resources, brand image and information technology contribute to the improvement in business performance. This confirms the works of researchers who asserted that brand differentiates an organization from competitors, attract customers and promote repeat business. This therefore implies that, hotels in Ghana are likely to improve upon their business performance by designing strategic policies that will ensure that they constantly improve and enhance their human resource capabilities which will consequently lead to an increased in business performance. Similarly, it is believed the presence of the industry forces was affected due to the simultaneous moderation. In effect, this implies that when hotel firms are able to effectively manage industry forces, they ultimately benefit from higher business performance such as growth in profitability, sales growth, customer satisfaction and customer retention. Therefore, an effective management of industry forces by managers of hotels contributes significantly to the attainment of business performance.

\section{REFERENCE}

1. Frese, M., Rousseau, D. M., \& Wiklund, J. (2014). The Emergence of Evidence-Based Entrepreneurship. Entrepreneurship theory and Practice, 38(2), 209-216.

2. Miyamoto, M. (2015). Application of competitive forces in the business intelligence of Japanese SMEs. International Journal of Management Science and Engineering Management, 10(4), 273-287.

3. Barney, J. B. (2014). How marketing scholars might help address issues in resource-based theory. Journal of the academy of marketing science, 42(1), 24-26.

4. Tongchaiprasit, P., \& Ariyabuddhiphongs, V. (2016). Creativity and turnover intention among hotel chefs: The mediating effects of job satisfaction and job stress. International Journal of Hospitality Management, 55, 33-40.

5. Xuhua, H., Spio-Kwofie, A., Udimal, T. B., \& Addai, M. (2018). Entrepreneurial innovation strategies; an option for small hotels' growth in Ghana. Journal of Global Entrepreneurship Research, 8(1), 30.

6. Lumpkin, G. T., \& Dess, G. G. (1996). Clarifying the entrepreneurial orientation construct and linking it to performance. Academy of management Review, 21(1), 135-172.

7. Barney, J. (1991). Firm resources and sustained competitive advantage. Journal of Management, 17(1), 99-120.

8. Porter, M. E. (1985). Competitive advantage: creating and sustaining superior performance. 1985. New York: FreePress, 43, 214.

9. Baradarani, S., \& Kilic, H. (2018). Service innovation in the hotel industry: culture, behavior, performance. The Service Industries Journal, 38(13-14), 897-924.

10. Hu, X., Spio-Kwofie, A., \& Antwi, H. A. (2018). The Influence of Entrepreneurial Orientation and Business Performance: A Study of Small Hotels in Ghana. European Journal of Contemporary Research, 7(1).

11. Vega-Vázquez, M., Cossío-Silva, F. J., \& RevillaCamacho, M. Á. (2016). Entrepreneurial orientation-hotel performance: Has market orientation anything to say? Journal of Business Research, 69(11), 5089-5094.

12. Köseoglu, M. A., Ross, G., \& Okumus, F. (2016). Competitive intelligence practices in hotels. International Journal of Hospitality Management, 53, 161-172.

13. Jogaratnam, G. (2017). The effect of market orientation, entrepreneurial orientation and human capital on positional advantage: Evidence from the restaurant industry. International Journal of Hospitality Management, 60, 104-113.

14. Vomberg, A., Homburg, C., \& Bornemann, T. (2015). Talented people and strong brands: The contribution of human capital and brand equity to firm value. Strategic Management Journal, 36(13), 2122-2131.

15. Pervan, M., Curak, M., \& Pavic Kramaric, T. (2017). The Influence of Industry Characteristics and Dynamic Capabilities on Firms' Profitability. International Journal of Financial Studies, 6(1), 4.

16. Grigore, A. M. (2014). Book Publishing Business in Romania-An Analysis from the Perspective of Porter's Five Force Model. Revista de Management Comparat International, 15(1), 31.

17. Leonidou, L. C., Leonidou, C. N., Fotiadis, T. A., \& Zeriti, A. (2013). Resources and capabilities as drivers of hotel environmental marketing strategy: Implications for competitive advantage and performance. Tourism Management, 35, 94-110.

18. Wu, C. W., \& Huarng, K. H. (2015). Global entrepreneurship and innovation in management: Elsevier.

19. Aissa, S. B., \& Goaied, M. (2016). Determinants of Tunisian hotel profitability: The role of managerial efficiency. Tourism Management, 52, 478-487.

20. Saleem, H., \& Raja, N. S. (2014). The impact of service quality on customer satisfaction, customer loyalty and brand image: Evidence from hotel 
industry of Pakistan. Middle-East Journal of Scientific Research, 19(5), 706-711.

21. Beglari, S. M. (2017). Effective Competitive Strategies of US In Vitro Device Manufacturers.

22. Della Corte, V. (2016). The strategic environment of hotel chains The Routledge Handbook of Hotel Chain Management (pp. 83-94): Routledge.

23. Nieves, J., \& Diaz-Meneses, G. (2016). Antecedents and outcomes of marketing innovation: An empirical analysis in the hotel industry. International Journal of Contemporary Hospitality Management, 28(8), 1554-1576.

24. Pervan, M., Curak, M., \& Pavic Kramaric, T. (2018). The Influence of Industry Characteristics and Dynamic Capabilities on Firms' Profitability. International Journal of Financial Studies, 6(1), 4.

25. Raguseo, E., Neirotti, P., \& Paolucci, E. (2017). How small hotels can drive value their way in infomediation. The case of 'Italian hotels vs. OTAs and TripAdvisor'. Information \& Management, 54(6), 745-756.

26. Gallucci, C., Santulli, R., \& Calabrò, A. (2015). Does family involvement foster or hinder firm performance? The missing role of family-based branding strategies. Journal of Family Business Strategy, 6(3), 155-165.

27. Berezina, K., Bilgihan, A., Cobanoglu, C., \& Okumus, F. (2016). Understanding satisfied and dissatisfied hotel customers: text mining of online hotel reviews. Journal of Hospitality Marketing \& Management, 25(1), 1-24.

28. Dedeke, A. N. (2016). Travel web-site design: Information task-fit, service quality and purchase intention. Tourism Management, 54, 541-554.

29. Evans, N. G. (2016). Sustainable competitive advantage in tourism organizations: A strategic model applying service dominant logic and tourism's defining characteristics. Tourism Management Perspectives, 18, 14-25.

30. Porter, M. E., \& Millar, V. E. (1985). How information gives you competitive advantage: Harvard Business Review Cambridge, MA.
31. Gomezelj, D. O. (2016). A systematic review of research on innovation in hospitality and tourism. International Journal of Contemporary Hospitality Management, 28(3), 516-558.

32. Lin, Y., \& Wu, L. Y. (2014). Exploring the role of dynamic capabilities in firm performance under the resource-based view framework. Journal of Business Research, 67(3), 407-413.

33. Lopes, M. (2016). The hospitality industry.

34. Silva, R. (2015). Multimarket contact, differentiation, and prices of chain hotels. Tourism Management, 48, 305-315.

35. Ivanova, M., \& Ivanov, S. (2015). The nature of hotel chains: An integrative framework. International Journal of Hospitality \& Tourism Administration, 16(2), 122-142.

36. Richard, B., \& Cleveland, S. (2016). The future of hotel chains: Branded marketplaces driven by the sharing economy. Journal of Vacation Marketing, 22(3), 239-248.

37. Ivanova, M., \& Ivanov, S. (2015). Affiliation to hotel chains: Hotels' perspective. Tourism Management Perspectives, 16, 148-162.

38. Benitez-Amado, J., Llorens-Montes, F. J., \& Fernandez-Perez, V. (2015). IT impact on talent management and operational environmental sustainability. Information Technology and Management, 16(3), 207-220.

39. Hair Jr, J. F., Hult, G. T. M., Ringle, C., \& Sarstedt, M. (2016). A primer on partial least squares structural equation modeling (PLS-SEM): Sage Publications.

40. Bolarinwa, O. A. (2015). Principles and methods of validity and reliability testing of questionnaires used in social and health science researches. Nigerian Postgraduate Medical Journal, 22(4), 195.

41. Hajli, N. (2015). Social commerce constructs and consumer's intention to buy. International Journal of Information Management, 35(2), 183-191. 